\title{
O Processo de Reinserção Familiar sob a Ótica das Equipes Técnicas das Instituições de Acolhimento
}

\author{
Carolina Oliveira de Brito ${ }^{1}$ \\ Edinete Maria Rosa \\ Zeidi Araújo Trindade \\ Programa de Pós-Graduação em Psicologia da Universidade Federal do Espírito Santo, \\ Vitória, Espírito Santo, Brasil
}

\begin{abstract}
Resumo
Profissionais das instituições de acolhimento vêm encontrando sérias dificuldades para promover a reinserção familiar das crianças e adolescentes, contribuindo para um prolongado tempo de institucionalização, que pode trazer inúmeras consequências negativas para o desenvolvimento saudável destas. Este estudo investigou a visão dos integrantes das equipes técnicas de seis instituições de acolhimento de um município do Espírito Santo acerca do processo de reinserção familiar de crianças e adolescentes. Foram realizados dois grupos focais, com a participação de 12 técnicos. Também foi utilizada a técnica da inserção ecológica e os dados foram registrados em Diário de Campo. Os resultados indicam credibilidade e envolvimento dos técnicos nos processos de reinserção familiar, apesar das dificuldades por eles destacadas: a não adesão das famílias aos programas de apoio familiar, a incompreensão de alguns componentes da rede sobre a família extensa, a falta de recursos financeiros das famílias e a valorização da instituição, por parte dos pais, como local ideal para seus filhos permanecerem. Superar a visão de família nuclear, promover articulação com a rede sócio assistencial e jurídica e aplicar o princípio da brevidade são os grandes desafios que as equipes técnicas devem vencer para promover com mais eficiência a reinserção familiar.
\end{abstract}

Palavras-chave: Acolhimento institucional, crianças e adolescentes, institucionalização, reinserção familiar.

\section{Family Reinsertion Processes as Seen from the Standpoint of Foster Care Technical Teams}

\begin{abstract}
Foster care professionals have encountered difficulties in their attempt to promote the reinsertion of children and adolescents with their families within their own community. This fact alone is what forces those young persons to remain in foster care institutions for a longer period of time than is thought advisable. This, in turn, triggers off a great number of negative impacts on the development of those youths as human beings. As regards the process of family reinsertion, this paper investigated the technical teams of six foster care institutions located in Espírito Santo, Brazil. Two focus groups were conducted,
\end{abstract}

Endereço para correspondência: Rua Amélia Tartuce Nasser, 980/502, Jardim da Penha, Vitória, ES, Brasil 29060-110. E-mail: carolina_psicologa@hotmail.com

Apoio Financeiro: Coordenação de Aperfeiçoamento de Pessoal de Nível Superior (Capes).

Este artigo faz parte da dissertação de mestrado de autoria de Carolina Oliveira de Brito, sob orientação da prof $^{\mathrm{a}}$ Edinete Maria Rosa, e colaboração da prof ${ }^{\mathrm{a}}$ Zeidi Araújo Trindade. 
with the participation of 12 technicians. The ecological insertion technique was also used, and the data were all recorded in a Field Journal. The results indicate credibility and involvement of the technicians in the reinsertion process despite all these difficulties: the non-adherence of the families to the family support program; the lack of understanding of some of the network's components as regards extended families; the family's insufficiency of financial resources; and the overvaluation of the institution as the ideal environment where their children can stay. Questioning the notion that all families are nuclear, encouraging improvements in the interaction between foster care institutions and the support network, and applying the principle of brevity are the major challenges that technical teams have to face in order to efficiently promote family reinsertion.

Keywords: Foster care, children and adolescents, institucionalization, family reunification.

\section{El Procedimiento de Reintegración Familiar según Experiencias del Personal de Instituciones de Amparo}

\section{Resumen}

Los profesionales de instituciones de amparo están encontrando sérias dificultades al fomentar la reintegración familiar de niños y adolescentes, lo cual ocasiona una permanencia más prolongada en estas instituciones - situación que provoca numerosas consecuencias negativas para el sano desarrollo de los mismos. Este estudio tuvo como objetivo conocer la opinión de los integrantes del personal técnico de seis instituciones de amparo de un municipio de Espírito Santo, Brasil, sobre la reintegración familiar. Fueron realizados dos grupos focales, con la participación de 12 técnicos. Fue utilizada también la técnica de inserción ecológica, y los datos fueron registrados en Diario de Campo. Los resultados demuestran la credibilidad y comprometimiento por parte del personal técnico, a pesar de las dificultades por ellos registradas: la falta de apoyo de las familias en relación a los programas de ayuda familiar, la intransigencia de algunos integrantes de la red respecto a la familia extensa, la falta de recursos financieros de las familias y la valorización de la institución, por parte de los padres de familia, como establecimiento ideal para la permanencia de sus hijos. Superar la opinión del familia nuclear, fomentar el acoplamiento con la red socio-asistencial y jurídica y poner en práctica el principio de la brevedad son los grandes desafíos que el personal técnico debe vencer para impulsar con más eficiencia la reintegración familiar.

Palabras clave: Amparo institucional, niños y adolescentes, proceso de institucionalización, reintegración familiar.

O modelo de família considerado "ideal", ainda transmitido e predominante é o da família nuclear, mas é notável que esta não é a única forma de organização familiar existente nos dias de hoje. Percebe-se o crescente aumento dos diversos arranjos familiares, dentre os quais podemos mencionar a família monoparental (apenas um cônjuge e os filhos, geralmente matrifocais, isto é, chefiadas por mulheres) e a família recomposta (caracterizada pela presença de divorciados que geraram outras uniões).

As famílias de camadas populares são caracterizadas geralmente por serem regidas por um aspecto moral e por uma lógica de solidariedade. Assim, as famílias de classes populares geralmente não são organizadas por um núcleo, e sim por uma rede de confiança, na qual há uma obrigação moral de cuidado com o outro. Embora o modelo de família nuclear seja idealizado e aspirado pelas famílias de camadas populares, observa-se que a configuração familiar mais presente neste segmento é o de famílias matrifocais e extensas (Bastos, Alcântara, \& Ferreira-Santos, 2002).

O núcleo familiar tem sido assinalado enquanto contexto primordial de desenvol- 
vimento para crianças e adolescentes (Dessen \& Polonia, 2007) e, para que ocorra de maneira mais saudável, o Estatuto da Criança e do Adolescente (ECA) propõe como dever da família, da comunidade e da sociedade a garantia dos seus direitos. No entanto, quando a criança está ameaçada ou violada em seus direitos o Conselho Tutelar ou o Juizado da Infância e Juventude podem retirar a criança e colocá-la em instituições de acolhimento, como previsto no Artigo $\mathrm{n}$. 98 do ECA (1990).

Apesar da provisoriedade dessa medida de proteção, caracterizada no Artigo n. 101, muitas crianças e adolescentes permanecem durante anos acolhidas na instituição, observando-se um crescente aumento no número de crianças e adolescentes sob esta medida de proteção ( $\mathrm{Si}$ queira \& Dell'Aglio, 2006; Vasconcelos, Yunes, \& Garcia, 2009). Segundo dados do Ministério do Desenvolvimento Social (MDS), em 2010 somavam aproximadamente 37 mil crianças e adolescentes vivendo em 2624 instituições de acolhimento espalhadas pelo Brasil (Fundação Oswaldo Cruz [Fiocruz] \& Secretaria Nacional de Assistência Social [SNAS], MDS, 2011).

No Espírito Santo, contexto da presente pesquisa, constava a existência de 85 instituições de acolhimento, com 1092 crianças acolhidas, em sua maioria meninos, pardos, com média de 9,4 anos $(D P=5,0)$, que possuíam irmãos acolhidos na mesma instituição e que preservavam vínculos com a família de origem (54,7\%). Este Estado revelou-se com maior tempo médio de acolhimento institucional (média de 2,1 anos) (Melo, 2010).

O ECA considera função das instituições de acolhimento reavaliar periodicamente cada caso, informando à autoridade judiciária sobre a viabilidade do retorno à família de origem, além de manter programas destinados ao apoio e acompanhamento de egressos. No entanto, constata-se que os profissionais das instituições de acolhimento vêm encontrando sérias dificuldades para promover a reinserção familiar das crianças e adolescentes em situação de acolhimento institucional, em especial por dificuldades econômicas da família de origem (Silva, 2004).
Os estudos sobre esta realidade no Brasil são recentes e em quantidade ainda restrita. Indicam que as maiores dificuldades para o retorno das crianças e adolescentes às suas famílias de origem são: (a) as precárias condições socioeconômicas (Azôr \& Vectore, 2008; Silva, 2004); (b) a fragilidade, ausência ou perda do vínculo familiar, agravadas pelo elevado tempo de institucionalização (A. P. G. Oliveira \& Milnitsky-Sapiro, 2007; Silva, 2004; Siqueira, Massignan, \& Dell'Aglio, 2011); (c) o uso de substâncias psicoativas pelos responsáveis das crianças e adolescentes (Silva, 2004); (d) a falta de planejamento e acompanhamento das visitas periódicas das crianças e adolescentes institucionalizadas às famílias ou das famílias à instituição de acolhimento pelas equipes técnicas (Cavalcante, Costa Silva, \& Magalhães, 2010; Siqueira \& Dell'Aglio, 2007; Siqueira et al., 2011; Siqueira, Zoltowski, Giordani, Otero, \& Dell'Aglio , 2010); (e) ausência de políticas públicas e de ações institucionais de apoio à reestruturação financeira das famílias (A. P. G. Oliveira \& Milnitsky-Sapiro, 2007; Silva, 2004). Estudos internacionais, ainda que realizados em contextos diferenciados da realidade brasileira (Estados Unidos e Austrália), demonstram resultados semelhantes no que diz respeito a fatores que dificultam o processo de reinserção familiar, tais como o uso de substâncias por parte de pais/responsáveis (Fernandez \& Lee, 2011), déficit de habilidades parentais dos pais/responsáveis (Miller, Fisher, Fetrow, \& Jordan, 2006) e condições de pobreza (Kimberlin, Anthony, \& Austin, 2009).

Outros aspectos que tem sido mencionados na literatura nacional são as crenças distorcidas acerca do papel das instituições de acolhimento e dos papéis e deveres parentais na relação com os filhos. Desta maneira, a visão de incapacidade das famílias de classes populares para cuidar de seus filhos, por parte das equipes das instituições de acolhimento, tem se demonstrado um fator que contribui para o afastamento na relação com os familiares, proporcionando um aumento no tempo de institucionalização de crianças e adolescentes (Siqueira et al., 2011; Siqueira et al., 
2010; Vasconcelos et al., 2009). As famílias, por sua vez, muitas vezes apresentam falta de clareza do papel das instituições de acolhimento e procuram-nas para deixar os filhos sob seus cuidados, acreditando que as instituições teriam um poder de "consertar" os filhos (A. P. G. Oliveira $\&$ Milnitsky-Sapiro, 2007).

No Brasil é crescente o número de pesquisadores que tem se dedicado a estudar o acolhimento institucional de crianças e adolescentes, principalmente no campo da Psicologia, por se considerar que um prolongado tempo de institucionalização pode trazer sérios comprometimentos ao desenvolvimento da criança e do adolescente (Bellamy, 2008; Shechory \& Sommerfield, 2007). A Teoria Bioecológica do Desenvolvimento Humano de Urie Bronfenbrenner, pautada em uma visão sistêmica do desenvolvimento humano, permite pensar em contextos além do familiar em que crianças e adolescentes podem se desenvolver de maneira saudável. Bronfenbrenner privilegiou em seus estudos a análise de quatro aspectos multidirecionais inter-relacionados, o que é designado como modelo PPCT: "Pessoa, Processo, Contexto e Tempo" (Bronfenbrenner \& Morris, 2006).

As interações ocorridas no ambiente imediato do organismo com pessoas, objetos e símbolos, de uma forma recíproca e cada vez mais complexa, são entendidas por Bronfenbrenner e Morris (2006) como processos proximais. Foram considerados como elemento principal de sua teoria e, para que sejam efetivos, devem ser regulares e ter ocorrência em períodos duradouros de tempo.

A pessoa é compreendida pelos seus aspectos biológicos, físicos e psicológicos em interação com o ambiente (Bronfenbrenner \& Morris, 2006). Características do indivíduo em desenvolvimento, como suas convicções, temperamento, motivações teriam então impacto na maneira como os contextos são experenciados, tanto quanto os tipos de contexto nos quais a pessoa se insere.

O contexto de desenvolvimento se refere aos ambientes nos quais os indivíduos estão inseridos, e onde se desenrolam os processos de desenvolvimento. São eles: microssistema, mesossistema, exossistema e macrossistema. $\mathrm{O}$ ambiente mais próximo do sujeito é definido, de acordo com essa teoria, como microssistema, compreendido pelas relações que o mesmo estabelece face a face com outros integrantes do seu ambiente (Bronfenbrenner, 1979/2002). Assim, segundo este modelo, a família pode ser o primeiro microssistema do ser humano em desenvolvimento, no qual as pessoas interagem.

Outro nível de desenvolvimento do ambiente é o mesossistema, formado pela interação com outros ambientes também configurados como microssistemas. O mesossistema “. . . é formado ou ampliado sempre que a pessoa em desenvolvimento entra num novo ambiente" (Bronfenbrenner, 1979/2002, p. 21). O ambiente de que se trata nessa teoria não se refere exclusivamente a um espaço objetivo, ele pode ser uma nova rede social, um novo vínculo, uma comunicação, etc.

O exossistema consiste em ambientes que “... não envolvem a pessoa em desenvolvimento como um participante ativo, mas no qual ocorrem eventos que afetam, ou são afetados, por aquilo que acontece no ambiente contendo a pessoa em desenvolvimento" (Bronfenbrenner, 1979/2002, p. 21). O macrossistema, por sua vez, é formado pelos valores, crenças e ideologias presentes em uma sociedade que rege e orienta a formação e a manutenção dos sistemas de ordem inferior (micro-, meso- e exo) influenciando as formas de interação dos processos proximais e a visão de mundo que se tem (Bronfenbrenner, 1979/2002). Por fim, o tempo, ou cronossistema, consiste na sequência de eventos que constituem a história e o cotidiano da pessoa, nos quais ocorrem os processos proximais. Esta dimensão interage com as outras mencionadas anteriormente (Pessoa, Processo e Contexto), afetando os processos de desenvolvimento humano (Bronfenbrenner \& Morris, 2006).

O presente trabalho teve por objetivo investigar a visão dos integrantes das equipes técnicas de seis instituições de acolhimento de um município do Espírito Santo acerca do processo de reinserção familiar de crianças e adolescentes. 


\section{Método}

\section{Caracterização das Instituições de Acolhimento}

A pesquisa foi realizada em seis instituições de acolhimento que funcionavam sob regime de parceria com o Governo Municipal. A capacidade das mesmas era de até 12 crianças, embora no momento da pesquisa algumas instituições estivessem funcionando acima do limite proposto. O público atendido era definido de acordo com a idade e o sexo da criança, respeitando a política de não-desmembramento de irmãos, conforme observado na Tabela 1. As instituições A e $\mathrm{B}$ eram mantidas por uma mesma mantenedora, enquanto as instituições C, D, E e F eram mantidas por outra mantenedora.

Tabela 1

Caracterização das Instituições de Acolhimento, por Público Atendido

\begin{tabular}{lll}
\hline Idade & Meninos & Meninas \\
\hline Zero a seis anos & Instituição C & Instituições A, C \\
Seis a doze anos & Instituições D e E & Instituição A \\
Doze a dezoito anos & Instituições E e F & Instituição B \\
\hline
\end{tabular}

\section{Participantes}

Participaram da pesquisa 12 integrantes das equipes técnicas (quatro coordenadores, quatro psicólogos e quatro assistentes sociais), em sua maioria mulheres, com idade média de 33,16 anos $(D P=6,393)$, caracterizados de acordo com a Tabela 2. Percebe-se que apenas um dos integrantes das equipes era do sexo masculino, que em sua maioria eram jovens (com idade entre 25 a 46 anos), o que é compatível com o baixo tempo de trabalho nas instituições (de seis meses a seis anos). Nota-se também que o perfil de parte dos trabalhadores acompanha o que se encontra na área da Assistência Social, caracterizado por pessoas em início de atividade profissional (I. F. Oliveira, Dantas, Solon, \& Amorim, 2011).

Tabela 2

Caracterização dos Participantes da Pesquisa

\begin{tabular}{lllll}
\hline Identificação & Sexo & Idade & Tempo de serviço & Instituição em que trabalha \\
\hline P1 & Feminino & 35 anos & 4 anos & Instituição A \\
P2 & Feminino & 32 anos & 2 anos & Instituição A \\
P3 & Feminino & 35 anos & 3 anos & Instituição A \\
P4 & Feminino & 46 anos & 5 anos & Instituição B \\
P5 & Feminino & 30 anos & 3 anos & Instituição B \\
P6 & Feminino & 44 anos & 6 anos & Instituição B \\
P7 & Feminino & 25 anos & 6 meses & Instituições C e F \\
P8 & Feminino & 27 anos & 2 anos & Instituições C e F \\
P9 & Feminino & 28 anos & 6 meses & Instituição C \\
P10 & Masculino & 31 anos & 2 anos & Instituições D e E \\
P11 & Feminino & 35 anos & 1 ano & Instituições D e E \\
P12 & Feminino & 30 anos & 1 ano e 6 meses & Instituições C, D, E e F
\end{tabular}

\section{Procedimentos e Instrumentos para Coleta de Dados}

O processo de coleta de dados foi realizado com base no procedimento da inserção ecoló- gica, que propõe um engajamento no ambiente ecológico no qual os participantes da pesquisa vivem, com o objetivo de conhecer a sua realidade (Eschiletti Prati, Couto, Moura, Poletto, \& 
Koller, 2008). Esta etapa foi realizada pela pesquisadora após leitura de artigos que abordavam essa estratégia, sendo efetuada através do acompanhamento semanal das atividades realizadas pelas equipes técnicas (tais como visitas domiciliares, reuniões na Vara da Infância e Juventude, reuniões de estudo de caso com a rede sócio assistencial e eventos comemorativos), durante um total de cinco meses. Os dados da inserção ecológica foram sistematicamente registrados em um diário de campo, organizado de forma a permitir o registro das relações, da rotina da instituição e dos espaços frequentados pelas crianças e adolescentes.

Além disto, foram realizados Grupos Focais com as equipes técnicas das instituições de acolhimento. Segundo De Antoni et al. (2001), os grupos focais objetivam a coleta de dados por meio de interações grupais, considerando a visão dos integrantes do grupo frente a um tema através de suas próprias palavras e comportamentos.

Foram realizados dois grupos com as equipes técnicas das instituições de acolhimento, sendo um com as instituições A e B, totalizando seis participantes, e outro com as instituições $C$, $\mathrm{D}, \mathrm{E}$ e $\mathrm{F}$, com a mesma quantidade de participantes. Os encontros foram realizados separadamente visando impedir que os relatos fossem polarizados em função das diferentes mantenedoras. Durante o grupo focal foi investigado como se estruturam os processos de reinserção familiar, e quais os principais entraves que as equipes encontram para que estes processos se concretizem, além da concepção de família existente entre os integrantes das equipes técnicas das instituições pesquisadas.

Os participantes foram informados individualmente sobre o tema e os objetivos da pesquisa, através de uma carta-convite para participação no grupo, sendo esta de caráter voluntário. Dos 14 integrantes das equipes das instituições acolhedoras pesquisadas, 12 atenderam ao convite, sendo que dois coordenadores não puderam comparecer devido à intensa rotina de atividade nas instituições, totalizando uma amostra de $85,7 \%$ dos profissionais técnicos.

Os encontros ocorreram no mesmo dia, tendo sido realizados em uma sala do Programa de
Pós-Graduação em Psicologia da Universidade Federal do Espírito Santo. A escolha do local objetivou que a coleta fosse realizada fora do ambiente de trabalho dos participantes, tendo em vista que a realização dos grupos nas próprias instituições poderia gerar interrupções constantes, inclusive de crianças e adolescentes.

\section{Procedimento de Análise dos Dados e Considerações Éticas}

Os dados coletados no grupo focal foram transcritos e analisados a partir Teoria Bioecológica do Desenvolvimento Humano. Este estudo foi aprovado pelo Comitê de Ética em Pesquisa da Universidade Federal do Espírito Santo (processo $n^{\circ} 059 / 09$ ) e as diretorias técnicas das instituições de acolhimento autorizaram a sua realização através do "Termo de Concordância". Durante a realização dos grupos focais foram explicados os procedimentos adotados, sendo mencionado que os dados seriam gravados e posteriormente transcritos, garantindo-lhes o sigilo das informações. Foi realizada a leitura do "Termo de Consentimento Livre e Esclarecido" e, após as concordâncias, obteve-se a assinatura dos mesmos.

\section{Resultados / Discussão}

\section{O Processo de Reinserção Familiar}

As instituições pesquisadas acolheram 123 crianças e adolescentes no ano de 2009 , sendo que apenas 13 foram reinseridos à família. As equipes técnicas verificaram que o processo de reinserção familiar inicia-se com o acolhimento institucional da criança ou do adolescente, onde se faz o acolhimento inicial deste(a), levantando a sua história de vida. Assim, procura-se identificar a composição familiar da criança ou do adolescente, para que sejam feitos contatos e visitas, conforme fala a seguir:

. . . ai a gente identifica o núcleo inicialmente de onde ele saiu. É o primeiro lugar onde a gente vai investir. A criança morava com a avó, o avô? É lá naquele núcleo que a gente vai fazer o primeiro investimento. (P10) 
Após a avaliação inicial, construída a partir de visitas a este núcleo identificado, se for observado que não existe possibilidade de reinserção da criança ou do adolescente, a equipe busca outros núcleos familiares. Caso não existam outras possibilidades de investimento para reinserção em núcleos familiares de origem ou da família extensa, elabora-se um parecer indicando a inserção em família substituta, ou ainda a busca pela autonomia do adolescente para o desligamento por maioridade.

Nas situações em que se detecta a possibilidade de reinserção familiar (no ano pesquisado totalizavam 55 casos), a equipe técnica encaminha a família à rede sócio-assistencial objetivando dar apoio para a resolução dos problemas que levaram ao acolhimento. No entanto, as equipes sinalizaram que em muitos casos a família não adere a esses encaminhamentos.

Além disso, alguns profissionais também indicaram dificuldades quanto ao sexo da criança, assinalando maior permanência dos meninos nas instituições, uma vez que existe maior predileção dos candidatos a adotantes por meninas, como demonstrado na seguinte fala: "Quando a gente busca adoção com meninos, a gente não acha. Não existe família no Estado do Espírito Santo que queira menino de oito anos" (P8).

Já no período da adolescência a permanência de meninos é mais breve, devido à evasão das instituições e permanência nas ruas. Os profissionais indicaram que durante esta fase do desenvolvimento há uma prevalência de meninas em acolhimento, sugerindo a possibilidade de que nesta fase as meninas precisariam de maior proteção, permanecendo então acolhidas, conforme exemplificado pela fala: “. . . Menino adolescente que vem passando por violência ao longo da vida, desde a infância e que descobriu a situação de rua, consegue estabelecer uma rede na rua, ele não consegue dar conta do acolhimento" (P10).

Observou-se também uma influência em relação à idade na determinação do tempo de institucionalização de crianças e adolescentes. Assim, se a pessoa a ser reinserida é uma criança, as equipes avaliaram que se tem menos tempo para investir na família, uma vez que nesta idade a possibilidade de adoção é maior do que em crianças maiores ou adolescentes. Por outro lado, quando a reinserção familiar é voltada para adolescentes, as equipes mencionaram que possuem um tempo maior, tendo em vista que muitas vezes esta é a única possibilidade de desinstitucionalização, já que no Brasil a adoção tardia ainda não é uma realidade concreta (Mariano \& Rossetti-Ferreira, 2008).

Verificou-se, dessa forma, a influência dos aspectos da pessoa, tais como sexo e da idade da criança, nos processos de reinserção. Assim, quanto mais nova a criança, menos tempo para investimento no processo de reinserção familiar, uma vez que crianças mais novas e do sexo feminino têm maiores chances de adoção. Este dado implica em uma exigência especial na atuação da equipe técnica e impulsiona uma tendência jurídica a destituir o poder familiar o mais rápido possível quando se trata de crianças pequenas para "não se perder" a chance de uma adoção. Se por um lado o período de atuação da equipe técnica deve ser agilizado por se tratar de pessoas em rápido desenvolvimento, por outro pode-se reforçar uma visão higienista da justiça, que desautoriza principalmente os pobres na sua função parental (Livramento, Brasil, Charpinel, \& Rosa, 2012).

\section{Alguns Entraves no Processo de Rein- serção Familiar}

Durante o período de inserção ecológica observou-se que algumas instituições funcionavam acima da capacidade de acolhimento, tais como as instituições A, B, C e D e, diante desta situação, muitas equipes ficavam sem saber o que fazer para promover a mudança desta realidade, conforme observado na fala a seguir: " $E$ assim, a gente tá com muito medo que a solução seja criar mais abrigos, sabe? Ai eles vão encher todos os abrigos que criarem ... Ao invés de agilizar os processos" (P12).

Em alguns casos, a situação era ainda mais crítica, com a presença de seis bebês e sete crianças pequenas em uma instituição com apenas dois educadores, dificultando a estimulação adequada das habilidades necessárias neste período do desenvolvimento. No que tange aos 
efeitos para as equipes técnicas, estas indicaram durante a inserção ecológica que muitas vezes não conseguiam realizar todos os procedimentos que gostariam, tais como visitas domiciliares e contato frequente com a família. Verificou-se que as relações estabelecidas entre cuidadores e crianças/adolescentes (processos proximais) muitas vezes eram prejudicadas pela escassez do tempo que elas podiam dedicar a cada criança, o que tornava o trabalho mecanizado.

O Plano Nacional de Promoção, Defesa e Garantia dos Direitos de Crianças e Adolescentes à Convivência Familiar e Comunitária prevê a proporção de um cuidador/educador para cada dez crianças e/ou adolescentes, indicando a necessidade de aumento desta proporção quando houver usuários com idade inferior a um ano. Sugere então a proporção de um cuidador/educador para cada oito usuários, quando houver um usuário com necessidades específicas, ou ainda de um cuidador/educador para cada seis crianças e/ou adolescentes, quando na presença de dois ou mais usuários com demandas específicas (Conselho Nacional dos Direitos da Criança e do Adolescente [CONANDA], Conselho Nacional de Assistência Social [CNAS], Secretaria Especial dos Direitos Humanos [SEDH], \& MDS, 2006). No entanto, percebeu-se que essa proporção ainda é insuficiente, principalmente para instituições cujo público-alvo era de crianças de zero a seis anos. Observou-se, por exemplo, a presença de seis bebês e sete crianças pequenas em uma só instituição, o que indica que apenas três cuidadores/educadores não seriam suficientes para um atendimento adequado para propiciar as condições ideias para o desenvolvimento saudável destas crianças.

Assim, uma característica presente no microssistema (alta proporção de crianças por profissionais) afetou também o mesossistema, uma vez que a relação da equipe técnica com a família não se dava com a frequência e forma desejáveis, o que prejudicou uma aproximação entre familiares e crianças. Dessa forma, pode-se questionar se a baixa frequência de visitas dos familiares às crianças se devia às características da própria família ou decorria da falta de investimento da equipe técnica nesta relação.
As equipes indicaram dificuldades na relação com as famílias no que diz respeito: (a) a pequena quantidade de visitas que as crianças e adolescentes recebiam nas instituições; (b) a visão das famílias em relação às instituições de acolhimento como empecilhos à reinserção familiar e (c) a baixa adesão das famílias aos encaminhamentos propostos, como identificado na seguinte fala:

Eu tô com um caso lá agora que a gente manda pra unidade [de saúde], mas isso tá tão descolado da história, que a família não consegue aderir. Você solicita, vai lá, chama a família, sensibiliza, mas não cola, não adere. Vai num atendimento, não vai no outro, e isso vai refletindo. (P4)

No que tange à visão das famílias em relação às instituições de acolhimento, as equipes afirmaram que muitas delas percebem estes espaços como sendo mais benéficos aos filhos. Desvalorizavam-se as relações estabelecidas entre as crianças e os familiares, em detrimento da estrutura física das instituições, tais como quantos quartos possuíam, quantas crianças ou adolescentes dormiam em cada quarto, a presença de televisão, computador e videogame, e também a quantidade de refeições que elas faziam ao longo do dia, como se pode perceber na fala seguinte:

Ai algumas famílias quando vão aos espaços de acolhimento tem um choque, que é um choque de realidade muito grande com a nova política. Algumas famílias vão na primeira vez [na instituição] e na outra semana já não vão mais. Pô, lá come cinco vezes no dia, tá indo pra escola... (P1)

As equipes citaram que muitas vezes elas discutem com as famílias as diversas formas de cuidado para com os filhos, destacando as limitações e os aspectos positivos que existiam em cada uma. Desta maneira, os profissionais mostravam às famílias que a limitação econômica por si só não poderia se constituir em motivo de acolhimento institucional, como visto na seguinte fala:

Quando ela chegou naquele serviço e viu assim que "Ah, aqui meu sobrinho tá tão bem cuidado que pra que eu vou... e eu também 
não tenho muito tempo". Mas na conversa de como ela cuida dos filhos dela, pela conversa, pelo relato dela, era com muito afeto, com muita provisão. (P9)

Se referindo às relações da instituição com os outros microssistemas das crianças, os técnicos afirmam que as famílias atribuíram papel de acolhimento e proteção à instituição, sendo a instituição mais valorizada enquanto um local ideal ao desenvolvimento dos filhos. Dada a constatação de que esta avaliação se pautava na comparação que os familiares faziam das condições materiais apresentadas pelas instituições e suas próprias condições, podemos inferir que o estado de pobreza das famílias se constituía no principal motivo à crença da necessidade de permanência de seus filhos na instituição.

Fonseca (1987) sinalizou em estudo realizado em uma vila porto-alegrense que grande parte das crianças possuía histórico de institucionalização. Após observar as causas deste fenômeno, percebeu-se uma forte relação com o fenômeno da circulação de crianças, no qual crianças eram deixadas com familiares ou vizinhos para serem providas. No entanto, a autora observou que não ocorria a quebra do vínculo familiar. Mesmo nos casos de institucionalização e após anos sem manter contato com os filhos, as famílias ainda faziam menção aos filhos institucionalizados.

Assim, percebeu-se que a visão da instituição de acolhimento enquanto um local apropriado para o desenvolvimento dos filhos e retorno ao seio familiar após a idade adulta se mostrou presente ainda nos dias de hoje, corroborando o estudo de Fonseca (1987), que menciona a função destes espaços enquanto "internato do pobre". Se o Estado não interfere nas condições mínimas para o efetivo cumprimento dos deveres constitucionais da família (sustento, guarda e educação), ele próprio legitima a visão das famílias, já verificada em outros estudos, a respeito do julgamento de superioridade da instituição em relação à família (A. P. G. Oliveira \& Milnitsky-Sapiro, 2007).

Percebe-se que esta visão existe desde antes do ECA (Trindade, 1984), e não foi rompida mesmo após duas décadas da sua promulgação.
Isso demonstrou uma dificuldade na alteração das crenças existentes, indicando que as mudanças no macrossistema podem demandar longos períodos de tempo, o que reflete na dificuldade de transformação das políticas públicas. Esses dados que indicam a interdependência de valores macrossistêmicos com as práticas parentais corroboram os estudos realizados por Bronfenbrenner (1986) e indicam que as intervenções psicossociais devem ser planejadas e executadas de forma sistêmica em toda rede de proteção, operando mudanças lentas ao longo de períodos históricos.

Verificou-se que as equipes percebiam que alguns membros da rede sócio-assistencial e jurídica também possuíam uma visão acerca das instituições de acolhimento que eram prejudiciais à reinserção familiar:

Os próprios órgãos de defesa e promoção têm equivocos em relação ao que é o acolhimento institucional. Assim que eu entrei no abrigo fui procurar um pouco da história de uma adolescente, um técnico da Vara da Infância falou: "não mexe nessa família não, fulana tá tão bem com vocês!". (P4)

Pôde-se perceber que essas concepções podem afetar a visão que as próprias equipes possuíam acerca das instituições de acolhimento, conforme se observou na fala a seguir: "Então assim, a gente também tá começando a pensar nessa perspectiva, talvez o abrigo seja um cuidador durante a fase da infância e da adolescência mesmo, para algumas famílias" (P8).

Buscou-se também apreender a concepção de família das equipes técnicas e constatou-se que elas consideram a presença de vários arranjos familiares. Assim, afirmaram que poderiam ser compostos tanto por pessoas com as quais as crianças e adolescentes possuíam laços consanguíneos, tanto por pessoas com quem possuíam relações de proximidade. Isso pode ser observado na fala a seguir: "Eu considero assim, a família como um vínculo, e que pode oferecer alguma coisa de família, e de que família dentro da perspectiva que o municipio tá querendo adotar, que tá vinculado às relações de consanguinidade e afinidade, né?" (P4). 
Essa ideia rompe com a naturalização das famílias nucleares e poderia ampliar as possibilidades reais da criança se manter sob os cuidados da família extensa. No entanto, as equipes assinalaram que alguns integrantes da rede de apoio social não possuíam esta mesma concepção de família. Isso pode afetar negativamente a articulação das equipes com o exossistema das crianças e adolescentes em acolhimento institucional, como comprova a fala a seguir:

P11: Porque nosso juiz aqui tem mania de não decidir nada por ele. Tudo ele quer dar vistas pro Ministério Público. E tem coisas que ele não precisaria fazer isso. Às vezes até um final de semana de um adolescente com um parente que quer se aproximar novamente...

P10: Porque não é parente de sangue.

Ficou claro que o andamento dos processos de reinserção familiar pode ser prejudicado por uma divergência entre a concepção de família das equipes técnicas e do exossistema, representado aqui pela rede sócio assistencial e também pelo sistema jurídico, uma vez que estes últimos apresentam uma visão que se afasta da realidade, valorizando um modelo nuclear de família. Por isso, a articulação com o exossistema torna-se um grande desafio para as equipes técnicas dos espaços de acolhimento. De acordo com Yunes, Miranda e Cuello (2004),

A integração pobre entre os abrigos e destes com os demais segmentos envolvidos com a questão da infância, só fazem agravar as deficiências das instituições, que podem representar mais risco, privação social, empobrecimento relacional do que proteção/ oportunidades de desenvolvimento das crianças. (p. 210)

Outro aspecto mencionado e amplamente discutido foi a morosidade dos processos na Justiça. Além disso, verificaram que a articulação da rede de atendimento não ocorre de maneira adequada, uma vez que os atores da Proteção Básica e da Proteção Especial não atuam em conjunto após a entrada da criança ou do adolescente na instituição. Assim, as equipes questionaram: "Se você for parar pra pensar a rede tá funcionan- do? A rede não tá funcionando, o que funciona são as interfaces que a gente enquanto técnicos estabelece com os serviços especificos praquele caso" (P1).

Por fim, observou-se a influência do fator tempo, constituinte da teoria de Bronfenbrenner, nos processos de reinserção familiar, no estabelecimento de estratégias de intervenção e investimento na família, em função da idade e sexo da criança, bem como nas interferências recebidas principalmente da justiça. A esse respeito os técnicos destacaram a morosidade da justiça como um empecilho para a reinserção familiar a despeito do que, efetivamente, tem se feito ou não para que as famílias adquiram as condições de reaverem o convívio com seus filhos.

\section{Considerações Finais}

As instituições de acolhimento são espaços que devem garantir o direito das crianças e adolescentes à convivência familiar e comunitária. Ao analisar os processos de reinserção familiar com a lente do Modelo Bioecológico do Desenvolvimento Humano, podem-se relativizar a responsabilidade unilateral dos profissionais que atuam nas instituições de acolhimento, ao evidenciarem-se as condições micro, meso, exo e/ou macrossistêmicas envolvidas na efetivação destes processos.

A análise dos dados indica que o processo de reinserção familiar traça o seguinte percurso: acolhimento inicial, com identificação da história de vida da criança ou do adolescente e dos seus núcleos familiares; realização de visitas familiares com vistas à avaliação sobre a possibilidade de efetivação do processo; encaminhamentos para a rede sócio-assistencial; e visitas domiciliares.

As reflexões trazidas pelas equipes técnicas a respeito do tempo (tempo da criança na instituição, morosidade da justiça e falta de tempo da equipe técnica para promover as ações necessárias com a família) revela ser este um dos pontos de tensão a ser enfrentado e resolvido na questão da reinserção familiar. O desdobramento de se praticar o princípio da excepcionalida- 
de e da brevidade na instituição de acolhimento acarreta uma rearticulação entre a instituição e sua rede de apoio, incluindo a justiça. Praticando o melhor interesse da criança as equipes precisam receber o reforço no número de profissionais e ter uma atuação mais conjunta com o poder jurídico.

Os técnicos envolvidos no presente estudo demonstraram credibilidade e envolvimento nos processos de reinserção familiar apesar das dificuldades por eles destacadas: a não adesão das famílias aos programas de apoio familiar, a incompreensão de alguns componentes da rede sobre a família extensa, a falta de recursos financeiros das famílias e a valorização da instituição como local ideal para seus filhos permanecerem.

A crença da instituição enquanto um local apropriado para o desenvolvimento das crianças, pelas famílias e por membros do poder jurídico, tem sido um fator que dificulta a desinstitucionalização das crianças e adolescentes. Observou-se que a retirada das crianças das famílias tem sido mais rápida do que a saída da instituição de acolhimento, o que indicou uma rigidez por parte das equipes técnicas nas ações para promoção da reinserção familiar. Desta forma, questiona-se se as próprias equipes não tem compartilhado a crença da instituição de acolhimento enquanto uma espécie de internato para as crianças de famílias pobres, necessitando-se de mais pesquisas neste campo.

Observou-se no presente trabalho a percepção das equipes técnicas acerca do processo de reinserção familiar. Sugere-se a realização de novos estudos que enfoquem também a percepção da família, das crianças e adolescentes envolvidos e de membros da rede sócio assistencial, trazendo descobertas para a compreensão de forma mais ampla sobre o fenômeno em questão. Desta forma, pode-se pensar coletivamente em melhorias para a promoção da reinserção familiar, sendo necessária uma maior articulação a nível local das políticas públicas existentes, da Proteção Básica à Proteção Especial, não deixando as responsabilidades pelas ações visando à reinserção familiar por conta somente das instituições de acolhimento.

\section{Referências}

Azôr, A. M. G. C., \& Vectore, C. (2008). Abrigar/ desabrigar: Conhecendo o papel das famílias nesse processo. Estudos de Psicologia (Campinas), 25(1), 77-89. doi:10.1590/S0103$-166 \times 2008000100008$

Bastos, A. C. S., Alcântara, M. A. R., \& Ferreira-Santos, J. E. (2002). Novas famílias urbanas. In E. R. Lordelo, A. M. Carvalho, \& S. H. Koller (Eds.), Infância brasileira e contextos de desenvolvimento (pp. 99-135). São Paulo, SP: Casa do Psicólogo.

Bellamy, J. L. (2008). Behavioral problems following reunification of children in long term foster care. Child and Youth Services Review, 30(2), 216-228. doi:10.1016/j.childyouth.2007.09.008

Bronfenbrenner, U. (1986). Ecology of the family as a context for human development: Research perspectives. Developmental Psychology, 22, 723742. doi:10.1037/0012-1649.22.6.723

Bronfenbrenner, U. (2002). A ecologia do desenvolvimento humano: Experimentos naturais e planejados (M. A. V. Veronese, Trad.). Porto Alegre, RS: Artes Médicas. (Original publicado em 1979)

Bronfenbrenner, U., \& Morris, P. (2006). The bioecological model of human development. In R. M. Lerner \& W. Damon (Eds.), Theoretical models of human development: Vol. 1. The handbook of child psychology ( $5^{\text {th }}$ ed.). New York: Wiley.

Cavalcante, L. I. C., Costa Silva, S. S., \& Magalhães, C. M. C. (2010). Institucionalização e reinserção familiar de crianças e adolescentes. Revista Mal-Estar \& Subjetividad, 10(4), 11471172. Recuperado em http://pepsic.bvsalud. org/scielo.php?script=sci_arttext\&pid=S1518$-61482010000400005 \& \operatorname{lng}=$ pt\&nrm $=$ iso

Conselho Nacional dos Direitos da Criança e do Adolescente, Conselho Nacional de Assistência Social, Secretaria Especial dos Direitos Humanos, \& Ministério do Desenvolvimento Social e Combate à Fome. (2006). Plano Nacional de Promoção, Defesa e Garantia dos Direitos de Crianças e Adolescentes à Convivência Familiar e Comunitária. Brasília, DF: Ministério do Desenvolvimento Social e Combate à Fome. Recuperado em 13 de junho, 2011, em http://www.mds.gov.br/assistenciasocial/ secretaria-nacional-de-assistencia-social-snas/ cadernos/plano-nacional-de-promocao-prote- 
cao-e-defesa-do-direito-de-criancas-e-adolescentes-a-convivencia-familiar-e-comunitaria/ plano-nacional-de-promocao-protecao-e-defesa-do-direito-de-criancas-e-adolescentes-a-convivencia-familiar-e-comunitaria

De Antoni, C., Martins, C., Ferronato, M. A., Simões, A., Maurente, V., Costa, F., \& Koller, S. H. (2001). Grupo focal: Método qualitativo de pesquisa com adolescentes em situação de risco. $A r-$ quivos Brasileiros de Psicologia, 53(2), 38-53.

Dessen, M. A., \& Polonia, A. C. (2007). A família e a escola como contextos de desenvolvimento humano. Paidéia (Ribeirão Preto), 17(36), 21-32. doi:10.1590/S0103-863X2007000100003

Eschiletti Prati, L. E., Couto, M. C. P. P., Moura, A., Poletto, M., \& Koller, S. H. (2008). Revisitando a inserção ecológica: Uma proposta de sistematização. Psicologia: Reflexão $e$ Crítica, 21(1), 160-169. doi:10.1590/S010279722008000100020

Estatuto da Criança e do Adolescente. (1990, 16 jul.). Lei 8.069, de 13 de julho de 1990. Dispõe sobre o Estatuto da Criança e do Adolescente e dá outras providências. Diário Oficial da União.

Fernandez, E., \& Lee, J. (2011). Returning children in care to their families: Factors associated with the speed of reunification. Child Indicators Research, 4(4), 749-765. doi:10.1007/s12187-0119121-7

Fonseca, C. (1987). O internato do pobre: Febem e a organização doméstica em um grupo Porto-alegrense de baixa renda. Temas IMESC, Sociedade, Direito, Saúde, 4(1), 21-39.

Fundação Oswaldo Cruz \& Secretaria Nacional de Assistência Social, Ministério do Desenvolvimento Social e Combate à Fome. (2011). Levantamento nacional das crianças e adolescentes em serviços de acolhimento. Brasília, DF: Ministério do Desenvolvimento Social e Combate à Fome. Recuperado em 13 de junho, 2011, em http://www.mds.gov.br/saladeimprensa/eventos/assistencia-social/encontro-nacional-de-monitoramento-do-suas-2011/arquivos/mesa-6/ Levantamento\%20Nacional\%20das\%20Criancas $\% 20 \mathrm{e} \% 20$ Adolescentes $\% 20 \mathrm{em} \% 20$ Servi$\cos \% 20 \mathrm{de} \% 20$ Acolhimento.pdf

Kimberlin, S. E., Anthony, E. K., \& Austin, M. J. (2009). Re-entering foster care: Trends, evidence, and implications. Children and Youth Services Review, 31, 471-481. doi:10.1016/j. childyouth.2008.10.003
Livramento, A. M., Brasil, J. A., Charpinel, C. P., \& Rosa, E. M. (2012). A produção de famílias negligentes: Analisando processos de destituição do poder familiar. Argumentum, 4(1), 173-186. Recuperado em http://periodicos.ufes.br/argumentum/article/view/2938/2725

Mariano, F. N., \& Rossetti-Ferreira, M. C. (2008). Que perfil da família biológica e adotante, e da criança adotada revelam os processos judiciais? Psicologia: Reflexão e Crítica, 21(1), 11-19. doi:10.1590/S0102-79722008000100002

Melo, A. A. (2010). Levantamento nacional das crianças e adolescentes em serviços de acolhimento. Recuperado em 13 de junho de 2011, em http://www.sst.sc.gov.br/arquivos/eca20/Ana_ Angelica_Melo_MDS_dados_SC.pdf

Miller, K. A., Fisher, P. A., Fetrow, B., \& Jordan, K. (2006). Trouble on the journey home: Reunification failures in foster care. Children and Youth Services Review, 28, 260-274. doi:10.1016/j. childyouth.2005.03.010

Oliveira, A. P. G., \& Milnitsky-Sapiro, C. (2007). Políticas públicas para adolescentes em vulnerabilidade social: Abrigo e provisoriedade. Psicologia: Ciência e Profissão, 27(4), 622-635. doi:10.1590/S1414-98932007000400005

Oliveira, I. F., Dantas, C. M. B., Solon, A. F. A. C., \& Amorim, K. M. O. (2011). A prática psicológica na proteção social básica do SUAS [Edição especial]. Psicologia \& Sociedade, 23, 140-149. doi:10.1590/S0102-71822011000400017

Shechory, M., \& Sommerfield, E. (2007). Attachment style, home-leaving age and behavioural problemas among residential care children. Child Psychiatry and Human Development, 37(4), 361-373. doi:10.1007/s10578-007-0051-z

Silva, E. R. A. (2004). O direito à convivência familiar e comunitária: Os abrigos para crianças e adolescentes no Brasil. Brasília, DF: Instituto de Pesquisa Econômica Aplicada.

Siqueira, A. C., \& Dell’Aglio, D. D. (2006). O impacto da institucionalização na infância e na adolescência: Uma revisão da literatura. Psicologia \& Sociedade, 18(1), 71-80. doi:10.1590/S010271822006000100010

Siqueira, A. C., \& Dell'Aglio, D. D. (2007). Retornando para a família de origem: Fatores de risco e proteção no processo de reinserção de uma adolescente institucionalizada. Revista Brasileira de Crescimento e Desenvolvimento Humano, 17(3), 
134-146. Recuperado em http://pepsic.bvsalud. org/scielo.php?script $=$ sci_arttext\&pid=S0104$-12822007000300014 \& \operatorname{lng}=$ pt\&nrm=iso

Siqueira, A. C., Massignan, L. T., \& Dell’Aglio, D. D. (2011). Reinserção familiar de adolescentes: Processos malsucedidos. Paidéia (Ribeirão Preto), 21(50), 383-391. doi:10.1590/S0103$-863 X 2011000300011$

Siqueira, A. C., Zoltowski, A. P., Giordani, J. P., Otero, T. M., \& Dell'Aglio, D. D. (2010). Processo de reinserção familiar: Estudo de casos de adolescentes que viveram em instituição de abrigo. Estudos de Psicologia (Natal), 15(1), 7-15. doi:10.1590/S1413-294X2010000100002

Trindade, Z. A. (1984). A realidade social de meninos institucionalizados (Dissertação de mestrado, Instituto de Psicologia, Universidade de São Paulo, SP, Brasil).
Vasconcelos, Q. A., Yunes, M. A. M., \& Garcia, N. M. (2009). Um estudo ecológico sobre as interações da família com o abrigo. Paidéia (Ribeirão Preto), 19(43), 221-229. doi:10.1590/S0103$-863 X 2009000200010$

Yunes, M. A. M., Miranda, A. T., \& Cuello, S. E. S. (2004). Um olhar ecológico para os riscos e as oportunidades de desenvolvimento de crianças e adolescentes institucionalizados. In S. H. Koller (Ed.), A ecologia do desenvolvimento humano: Pesquisa e intervenção no Brasil (pp. 197-218). São Paulo, SP: Casa do Psicólogo.

Recebido: 26/08/2013

$1^{a}$ revisão: 26/12/2013 Aceite final: 17/01/2014 